\title{
O ATO PEDAGÓgICO COMO POSSIBILIDADES DE PRAZER, ENGAJAMENTO E SIGNIFICADO: POSSIBILIDADES DE INCLUSÃO NO CONTEXTO DA EXCLUSÃO SOCIAL
}

\section{L'acte pédagogique comme des possibilités de plaisir, d'engagement et du signification: des possibilités d'inclusion dans le contexte de l'exclusion}

\begin{abstract}
Rita Vieira de Figueiredo Bon $e^{1}{ }^{1}$
Poderias me dizer como crescer? Ou é algo que não se transmite, como a melodia ou a magia? (Emily Dickinson)
\end{abstract}

\section{Resumo}

A inclusão de crianças com necessidades educacionais especiais é uma questão filosófica e político cultural. Filosófica, porque parte do princípio de que o espaço da escola deve ser dado para todas as crianças independente de raça, religião, condição social ou de desenvolvimento. Este é um espaço legitimo que não se questiona possibilidades ou não de nele estar incluída toda criança. Político cultural porque implica numa política de garantia do direito que todo cidadão tem de se beneficiar dos bens materiais e culturais da sociedade. A partir deste pressuposto, dedica-se, neste texto, à análise de uma experiência da aplicação da política de inclusão para a rede estadual do estado do Rio Grande do Norte, no início dos anos 90, a qual pode ser considerada um marco importante na consolidação da política de inclusão praticada nos dias atuais.

Palavras-chave: Exclusão, Política de Inclusão, Necessidades Educacionais Especiais.

Doutora (Ph.D.) em Psicopedagogia, Professora do Programa de Pós-Graduação em Educação da Universidade Federal do Ceará. Correio Eletrônico: rvieira@ufc.br 


\section{Résumé}

L'inclusion en classe ordinaire des élèves ayant des besoins particuliers est une question à la fois philosophique et politique. Philosophique parce qu'elle s'appuie sur l'idée que l'école ordinaire doit accueillir tous les élèves, peu importe leurs origines, leur réligion, leur condition sociale et économique ainsi que leur développement cognitif et affectivo-social. La légitimité de la présence de tous les élèves dans la classe ordinaire, quelles que soient leurs caractéristiques individuelles, peut difficilement être remise en question parce, d'un point de vue éthique, la non discrimination étant reconnue comme un principe fondamental dans la société brésilienne. Politique puisque dans la Constitution brésilienne, tout citoyen a le droit de profiter des biens matériels et culturels acquis par le société. À partir de ces idées et principes, une analyse de la conception et de l'application d'une polique d'inclusion dans l'État du Rio Grande do Norte au début des années 90 a été réalisée. Ce texte rend compte de l'analyse de cette expérience qui a fait oeuvre de pionnière etjoué un rôle important dans le recul de la discrimination et de la marginalisation des élèves ayant des besoins particuliers au Brésil. Mots-clefs : Exclusion, Marginalisation, Inclusion scolaire, Élèves ayant des besoins particuliers.

A inclusão escolar de crianças com necessidades educacionais especiais é uma questão filosófica e político cultural. Filosófica, porque parte do princípio de que o espaço da escola deve ser dado para todas as crianças independente de raça, cor, religião, condição social ou de desenvolvimento. Este é um espaço legítimo, em que não se questionam possibilidades ou não de nele estar incluída toda criança. É político cultural porque implica na garantia do direito que todo cidadão tem de se beneficiar dos bens materiais e culturais da sociedade. Segundo Booth e Ainscow (2000), a inclusão e a exclusão se expressam por três dimensões inter-relacionadas no cotidiano escolar, quais sejam: a dimensão da cultural inclusiva, da política inclusiva e a de práticas inclusivas. A primeira diz respeito à possibilidade de criação de uma comunidade escolar segura, acolhedora colaborativa e estimulante, na qual cada sujeito é valorizado. Esta comunidade acolhedora é a base para que 0 alunado conquiste melhores êxitos. Uma cultura inclusiva implica no desenvolvimento de valores que mobilizam as pessoas a pensarem, viverem e organizarem o espaço da escola incluindo nele todos os alunos. Esses valores são compartilhados por toda a comunidade escolar (estudantes, familiares, membros do conselho escolar, professores, funcionários e gestores). Os princípios que derivam dessa cultura escolar são os que guiam as decisões que se conectam com as políticas escolares e com as práticas escolares para apoiar a aprendizagem de todos por meio do processo contínuo de inovação e desenvolvimento da escola. 
A dimensão política, de acordo com Booth e Ainscow (2000), assegura que a inclusão seja o centro do desenvolvimento da escola permeando todas as políticas para que melhore a aprendizagem e a participação de todo o alunado. Nesta perspectiva, são consideradas como apoio todas as atividades que aumentam a capacidade da escola de dar respostas eficazes à diversidade de seus alunos. Esses apoios devem ser pensados da perspectiva do desenvolvimento dos alunos e não da perspectiva das instâncias administrativas da escola.

A dimensão das práticas educativas, ainda na visão dos autores acima citados, reflete as duas outras, a política e a cultural. Ela assegura que as atividades de sala de aula e as extra-escolares promovam a participação e 0 engajamento de todos os alunos. Ela deve considerar o conhecimento e as experiências vividas pelos alunos dentro e fora da escola. O ensino e os apoios se integram para orquestrar a aprendizagem e superar barreiras nestas aprendizagens bem como nas dificuldades de participação efetiva de todos os alunos nas práticas pedagógicas.

A reflexão sobre as mudanças necessárias na escola perpassa essas três dimensões, de modo que as experiências de desenvolvimento de uma política de inclusão devem focalizar essas dimensões. Pelo desenvolvimento de culturas inclusivas se podem produzir mudanças na política e nas práticas pedagógicas.

Permito-me aqui relatar e analisar uma experiência implementada com o objetivo de desenvolver uma política de inclusão para a rede de ensino do estado do Rio Grande do Norte no início dos anos 90. Naquela ocasião, nós respondíamos pelo Serviço de Educação Especial daquela rede e compreendemos que não poderíamos continuar legitimando a exclusão escolar de um número significativo de crianças identificadas como "especiais". Um aspecto que chamava atenção era a solicitação exagerada por parte das escolas da rede, para a avaliação e diagnóstico de crianças suspeitas de apresentarem algum tipo de "distúrbio ou deficiência". A queixa apresentada era a de que essas crianças não conseguiam se "adequar" ao ambiente escolar e nem progrediam em seus processos de aprendizagem. O procedimento da Secretaria na época era avaliar as crianças e encaminhar para as classes especiais aquelas identificadas como apresentando alguma "deficiência" mental ou de outra natureza, bem como condutas típicas.

Um exame inicial do procedimento da rede permitiu identificar as classes especiais como um canal de vazão daqueles alunos considerados os mais "difíceis" de serem trabalhados pela escola. Um diagnóstico inicial dos alunos das classes especiais permitiu identificar três problemas principais:

1 - A maioria desses alunos não apresentava "deficiências" reais. Eles eram justamente aqueles advindos de famílias cuja condição de exclusão social era fator determinante. 
2 - O segundo aspecto é que uma vez entrando na classe especial nunca mais saia dela. Ou seja, nessa modalidade de ensino existia apenas a porta de entrada.

3 - 0 terceiro, se relacionava à ausência de cumprimento dos objetivos das classes especiais, quais sejam propiciar adaptação e aprendizagens iniciais que "capacitassem" os alunos a serem integrados posteriormente no ensino regular.

Desse modo, a classe especial estava apenas legitimando a exclusão escolar de uma parcela significativa de alunos, justamente aqueles que sofriam diferentes formas de exclusão no contexto sociofamiliar. Ela rotulava os alunos de "incapazes" de aprenderem e de conviverem com os seus pares e não os instrumentalizava com conhecimentos e estratégias de inserção escolar que permitissem a eles se reapropriarem desse espaço coletivo de aprendizagem. Uma pesquisa feita (por amostragem em diversas classes especiais da rede) com o objetivo de avaliar a evolução desses alunos revelou que eles praticamente não se apropriavam dos conteúdos escolares, bem como não ampliavam suas estratégias de inserção escolar, visto que eram mantidos, na maioria das vezes, à parte do convívio com os demais alunos da escola. $\mathrm{O}$ ensino supostamente especial desenvolvido por professores especialistas nas deficiências dos alunos era pautado em minimização de conteúdos e práticas pedagógicas repetitivas. Tal quadro permitia questionar sobre a "contribuição" desse tipo de ensino para o crescimento dos alunos. A partir dessa constatação, iniciou-se um árduo processo de mobilização da rede para desconstruir a política e a cultura das classes especiais e incluir todos os alunos nas salas regulares. No Rio Grande do Norte, no início dos anos 90, havia uma confluência de fatores que favoreciam essa iniciativa. Ainda nos anos 80, algumas famílias vinculadas à Associação Síndrome de Down do Rio Grande do Norte decidiram que seus filhos não seriam escolarizados em classes especiais e os matricularam numa escola regular cujo objetivo era oferecer ensino de qualidade a todos os alunos. Família e escola deram-se as mãos e iniciaram um trabalho pioneiro construindo juntas as possibilidades de uma ação pedagógica efetiva e eficiente para todas as crianças. Se referindo a experiência de sua filha com Síndrome de Down, uma das primeiras alunas da referida escola, Moura (2005), relata:

Jamais imaginando que cumpriria um papel histórico de abrir espaços com responsabilidade científica para pessoas com síndrome de Down. O trabalho foi árduo, mas belíssimo! Erros e acertos permearam o processo na tessitura de uma real inclusão, quando sequer se falava ainda em inclusão no Brasil, senão apenas em integração, pois que estávamos ainda nos anos 80! E dali emergiu a verdade para nós, os pais pioneiros na busca de respostas: 
insofismavelmente, o convívio e a aprendizagem na escola comum, na escola regular, associada naturalmente à aceitação da família seriam a fórmula saudável de construir a base para a normalização da vida daqueles que nasceram com alguma diferença significativa, não sendo admissível, portanto, a negativa da convivência com as demais crianças. No que tange especificamente a Débora, merece referir que jamais freqüentou escola especial e, em face do seu contexto familiar, se instrumentalizou para ser participativa, abrindo ela própria seus espaços, reivindicando e questionando quando necessário. E assim cresceu "em graça e sabedoria".

Da experiência acima relatada, outras foram se desenhando e tomando lugar cada vez maior na consciência das famílias daquela associação. Isso favoreceu a discussão sobre o lugar de escolarização das crianças com Síndrome de Down e consequentemente essa discussão se estendeu para todas as outras possibilidades de escolarização. A rede municipal de Natal optou por escolarizar todas as crianças nas salas regulares sem jamais ter criado um espaço diferenciado de escolarização.

O tecido social era favorável à discussão quanto ao lugar de escolarização de todas as crianças e essa realidade permitiu que algumas pessoas que se sentiam engajadas nessa consciência pudessem avançar na luta pela inclusão de todas as crianças no ensino regular. Na época, a palavra de ordem era integração, que significava a criação das classes especiais nas redes regulares de ensino. Iniciamos então um trabalho de discussão com os técnicos da rede, com os profissionais das escolas e pais de alunos para discutirmos princípios educacionais e os objetivos das classes especiais. Estava claro que esse lugar de escolarização servia apenas para legitimar a exclusão escolar e deslocar o fracasso da escola para o fracasso dos alunos. O processo foi árduo. Enfrentamos barreiras de preconceitos, resistência e medo. Preconceito que era pautado no mito da homogeneidade, resistência à inauguração de novos parâmetros educacionais e medo pelo desafio que essa nova situação exigia. Professores do ensino regular diziam não estarem preparados para lidarem com os alunos "especiais" e os professores do ensino especial não se diziam preparados para ensinarem aos alunos "regulares". Os pais duvidavam da capacidade de seus filhos para se relacionarem com os alunos ditos normais e os pais destes, por sua vez, também temiam que aqueles novos alunos pudessem causar prejuízos na aprendizagem de seus filhos Os problemas eram muitos e o desfio enorme. A rede era grande (envolvia a capital e as cidades do interior) e era preciso garantir essencialmente a compreensão do sentido e do significado de poder escolarizar num mesmo espaço todas as crianças. Era preciso compreender que a escola, além de possibilitar a apropriação de valores e saberes socioculturais, é também o lugar que permite ao sujeito fazer um vínculo com a cultura e com o universo simbólico que rege as relações huma- 
nas. O ambiente da escola é um ambiente de aprendizagem de enfrentamento de regras e valores sociais e também o lugar de atravessamento das encruzilhadas psíquicas pelo desafio de lidar no cotidiano com o reconhecimento do próprio lugar e do lugar do outro. Aprender sobre a linguagem, sobre os valores e as regras sociais que perpassam a nossa cultura é também uma dimensão que integra as aprendizagens escolares. Neste aspecto, somente estando inserido nessa rede de interlocução social o sujeito se insere no discurso de seu grupo integrando um laço social que é fundado sobre a linguagem (LACAN, 1985).

Escolarizar junto e em conjunto com o outro implica reconhecer que o desenvolvimento e a aprendizagem da criança acontece essencialmente a partir das interações que ela estabelece com o outro e com o meio. A escola é um espaço privilegiado para esse desenvolvimento. É pelo enfrentamento do outro, dos desafios, das solicitações do meio que a criança se constitui e constitui o outro como sujeito. O impedimento desse convívio social, que é tão rico, tão desafiador, impede e limita o seu desenvolvimento.

A defesa de um espaço educacional diferenciado para as crianças com necessidades educativas especiais era na época, bem como ainda o é hoje, justificado com o argumento de que a escola não estava preparada para receber e trabalhar pedagogicamente com essas crianças. Hoje esse mesmo discurso aparece com o slogan da inclusão com responsabilidade, 0 que é um equívoco lamentável. Esse discurso é falso por duas razões principais. Primeiro, porque a escola não tem se mostrado muito preparada para lidar com quase todas as crianças. Tem fracassado na escola um grande número de crianças. Muitas delas porque, por alguma razão, têm dificuldades em se adequar às exigências escolares, ou seja, crianças que não apresentam necessidades educativas especiais, mas que a escola também se mostra despreparada para lidar pedagogicamente com elas. Na maioria das vezes, essas crianças são advindas de meios socioeconômicos desfavorecidos. Investigações realizadas no interior da escola pública indicam que o movimento de exclusão dos alunos atinge mais diretamente aqueles que não desenvolveram estratégias socioculturais de inserção escolar (FIGUEIREDO, MOTA, 2005; MOTA, 2004).

Mota (2003) realizou um estudo em uma escola pública de Campina Grande e constatou que as crianças que mais sofrem o processo de exclusão escolar são justamente aquelas que têm maior dificuldade em se apropriarem das estratégias de inserção escolar. Verificou-se, nesse estudo, que diferentes formas de exclusão são praticadas no cotidiano da escola. As justificativas escolares para a não adequação das crianças à escola podem ser relacionadas a "problemas no comportamento", na aprendizagem ou na adapta- 
ção das crianças. Mota (2002) verificou que as crianças identificadas como aquelas que não apresentavam condições de permanência na escola eram justamente aquelas cuja condição de exclusão social era mais evidente. Essas crianças enfrentavam dificuldades na apropriação dos conteúdos escolares (especialmente no que se refere à leitura e à escrita) produzidas pela forma como eram realizadas as práticas escolares. No entanto, o que de fato as desqualificavam no ambiente escolar não eram os "atrasos" na apropriação dos conteúdos curriculares, mas suas dificuldades em se apropriarem de conhecimentos socioculturais que funcionassem como estratégias de inserção no ambiente escolar. Segundo Figueiredo e Mota (2005),

Práticas escolares de distanciamento da criança da escola, relações baseadas na violência verbal, empecilhos para a utilização da biblioteca e pressão sobre o desempenho escolar da criança na escola são algumas evidências deste movimento contraditório entre o discurso defendido pela sociedade e as práticas pedagógicas escolares com repercussões no desempenho escolar dos alunos que apresentam atraso na aprendizagem da leitura.

No entanto, a reconstrução da imagem desses alunos como sujeitos leitores, prosseguem as autoras, deu-se pela apropriação de diversas estratégias de inserção escolar, revelando a subversão do lugar social de assujeitamento que lhes é atribuído, historicamente ${ }^{2}$, e atestando a desnaturalização da produção do atraso na escola.

Assim, ao estreitar a relação entre pobreza, competência e letramento, as conquistas dos alunos neste campo colaboram com a desconstrução do estigma de sujeitos incapazes, ao mesmo tempo em que permitem a problematização das deterioradas condições escolares de acesso, produção e distribuição do conhecimento, na escola pública para os membros das camadas trabalhadoras, o que fragiliza a disseminação da ideologia burguesa no campo educacional (FIGUEIREDO; MOTA, 2005).

Investigando o cotidiano das práticas escolares e a cultura que permeia as ações ali desenvolvidas, percebe-se que essa instituição não se preparou para trabalhar com a diversidade de seus alunos, permanece ainda centrada no mito da homogeneidade, sem reconhecer as diferenças inerentes a todas as crianças. É importante compreender que as diferenças são

2 Sob o ponto de vista do modelo socioeconômico vigente, os LDR são considerados população descartável do sistema (MOTA ROCHA, 2002) ou o que Sérgio Haddad conceituou, no Fórum Mundial da Educação (Porto Alegre, 2004), de subproletariado, porque considerados improdutivos. 
marcas eminentemente humanas, elas são desejáveis e são elas que enriquecem a comunidade humana. $\mathrm{O}$ humano se diferencia pela sua unicidade e singularidade, mas também se assemelha pelas suas necessidades de afeto e de pertencimento a um grupo social. Diferenças e semelhanças são inerentes ao humano. As desigualdades são socialmente produzidas por um contexto social injusto, pautado na exploração do homem sobre o homem. A escola reproduz em seu interior essas desigualdades, ignora a importância da diversidade para o processo de aprendizagem e desenvolvimento humano e exclui aqueles alunos cujas diferenças os desqualificam enquanto usuários de uma cultura pautada em valores de uma classe dominante.

A segunda razão diz respeito ao tempo e à forma requeridos pela escola para essa preparação. Há quanto tempo a escola se diz incapaz de lidar com as diferenças de seus alunos? Quanto tempo as famílias terão que esperar ainda para verem seus filhos convivendo e aprendendo com seus pares num espaço de convivência respeitoso e acolhedor? Que critérios podem ser utilizados para determinar quais alunos podem (ou não) estarem presentes no espaço coletivo de educação e aprendizagem? Esse tempo de preparação da escola não se constitui um tempo real de enfrentamento dos desafios das práticas e do cotidiano escolar, mas um tempo ideológico que pode ser utilizado como escusa para deixar a margem da escola alunos considerados incapazes dela se beneficiarem. A crença de que educar é muito mais que favorecer a apropriação de conteúdos acadêmicos, pois implica em ser e permitir ao outro revelar-se como sujeito num contexto de apropriação coletiva de valores e bens históricos e socialmente construídos, permitiu o entendimento de que o tempo de preparação da escola é o tempo presente. A escola é hoje, os alunos estão nela hoje e consequentemente não pode ser reportada a um tempo futuro.

Com base nesses princípios, foi possível organizar novas salas, distribuir alunos de classes especiais em diferentes salas regulares de ensino, organizaram-se os serviços de apoio, as equipes técnicas de acompanhamentos foram deslocadas da Secretaria de Educação para escolas e centros de atendimento, movimento que permitiu pouco a pouco que toda a rede reconhecesse a sala regular como o espaço legítimo de escolarização de todos os alunos. Esse movimento não foi um movimento tranqüilo e harmonioso, muitas discussões, discórdias e lutas de poder foram travadas. Entretanto, um saldo importante desse conflito foi a explicitação do caráter segregativo da classe especial porque a sua existência se funda no pressuposto de que algumas crianças têm modos de desenvolvimento e de aprendizagem tão diferentes e que lhes impedem de aprender como as demais. Esse princípio é a negação de que aprendemos a SER e o que 
vamos SER. Aprendemos e ensinamos valores, atitudes, normas e conhecimentos diversos. Aprendemos observando, escutando, sentindo, imitando, falando, silenciando, desafiando, testando, contestando. E, no momento em que nos defrontamos com a diferença, isto põe em cheque um questionamento sobre a autocentração do sujeito. A diferença nos leva a crescer e remeter nossos valores, atitudes e comportamentos a julgamento e, no momento em que valorizamos essa diferença, estamos reconhecendo que também somos sujeitos em construção. Então, defender a presença de crianças com deficiências em nossas salas de aula não é simplesmente um questão filosófica. Não significa apenas dizer que aceitamos trabalhar com as diferenças. É muito mais que isso, significa redimensionar o ato pedagógico de modo a somar as diferenças em sala de aula, para construirmos um novo olhar sobre a educação. Isso nos obriga enquanto educadores a estarmos sempre nos reconstituindo no processo, porque nós também somos sujeitos de conhecimento. Daí porque é tão difícil para nós educadores aceitarmos o fato de trabalharmos com o novo todo dia, com uma nova construção a cada dia.

E um aspecto importante é a mudança de perspectiva na ação do professor, que deve sair da perspectiva do espaço da aprendizagem individual, para o espaço de aprendizagem coletiva, e estar atento para as interações e o movimento do grupo como o eixo central da aprendizagem. Para além desses aspectos, conta ainda a dimensão da intenção e do desejo. A intenção implica nos aspectos mais objetivos do engajamento com sua atividade profissional. Esse engajamento está pautado no sentido e no significado que essa atividade recebe na vida daquele sujeito, enquanto que a dimensão desejante se vincula ao prazer que a atividade emana. A consciência desses elementos permite quebrar as barreiras dos preconceitos conduzindo ao enfrentamento das dificuldades e da construção de um movimento de inclusão num ambiente de exclusão social que é escola.

É necessário então que o professor aprenda e entenda o quanto é importante oferecer a todas as crianças um ambiente de aprendizagem rico de estimulação, de solicitação do meio, de interações, para que ela possa ter mais elementos para formular respostas. Não existe, portanto, nenhuma fórmula para trabalhar com alunos que apresentem deficiências, já que como qualquer outro sujeito epistêmico, ele apresenta variadas formas e possibilidades de aprender. Desse modo, é imprescindível compreender que o aluno é, antes de tudo, um aluno, independente da condição que ele apresenta e que é necessário se dispor a trabalhar com esse aluno oferecendo as solicitações mais diversificadas possíveis no trabalho pedagógico. O espaço da escola é o espaço da aprendizagem e de 
formação do sujeito, que aprende regras de convivência e limites, crescendo, construindo-se e construindo o outro. A escola que inclui é a escola que acolhe e garante o espaço de aprendizagem e de crescimento para todos os alunos.

\section{Referências}

BOOTH, T.; AINSCOW, M. Indicie de Inclusion: desarollamdo el aprendizaje y la participation en lãs escuelas. Bristol,UK:Center for Studies on Inclusive Education, , 2000.

FIGUEIREDO, R. V.; MOTA, S. R. As condições Sociais de Apropriação da Leitura e o Caráter Ideológico da Reprodução Social na Escola Pública. In: COLLQUI INTERNACIONAL DA AFIRSE,13., 2005, Manaus, Anais... Manaus, 2005.

LACAN, J. O seminário: livro 20. Mais ainda. Rio de Janeiro, RJ: Zahar, 1985. MOURA, M. S. Relato de experiência. Diversidade, Portugal, 2005. Prelo.

MOTA, S. R. da. Leitores da comunidade e crianças lêem histórias na escola: Programa de integração da criança remanescente à comunicação letrada. 2002. Tese (Doutorado) - Universidade Federal do Ceará, Ceará. 2002. 